\title{
1 LNG fueled barge for cold ironing: feasibility study 2 for the emission abatement in the Port of Genoa
}

\begin{abstract}
The scientific analysis presented in this paper aims at studying some maritime technical solutions for the electric energy generation and delivery to ships moored in port by means of LNG fueled generators installed onboard a floating unit. Two different scenarios regarding the LNG supply chain are supposed and some options for producing cleaner electric energy are then investigated. The reference area considered in this study is the old port of Genoa where the traffic of both passenger and cargo ships takes place. The paper presents an analysis concerning the main technical features of the considered solutions for an actual port calls scenario. The results regard dimensions and weights of the proposed floating units and the most significant characteristics of the generation equipment, as far as average load factor, fuel consumption and cost are concerned.
\end{abstract}

\author{
Keywords \\ Power supply $\cdot$ Alternative fuels $\cdot \mathrm{LNG} \cdot \mathrm{HVSC}$
}

\section{Introduction}

19

On a global scale, by 2030 the United Nations have planned goals dealing with energy efficiency and cleaner fossil-fuel management, promoting investment in both infrastructure and technology for a more eco-friendly environment. This new kind of scenario will involve the maritime activities and the international shipping as confirmed by Annex VI of IMO's pollution prevention treaty (MARPOL).

The strong interest to cut emissions from maritime shipping is supported by a regulatory framework consisting of international regulations, European directives and national laws regarding the emissions thresholds from ships in port and possible solutions to comply with this need (Coraddu, 2014). The current regulations relating to such issues are:

- EU Directive 2005/33/EC, requiring for marine fuels a maximum sulfur content of $0.1 \%$ and $1.5 \%$ by mass in European ports and in exclusive economic zones respectively;

- EU Directive 2014/94/EU, requiring the installation of LNG refueling stations placed in the core TEN-T ports by 2025;

- Annex VI of the MARPOL, establishing, for the pollutant emission from marine fuels, sulfur limits and NOx content up to threshold values;

- EU Directive 2006/339/EC, involving the installation of electric power stations in the port for supplying energy to ships while at berth;

- Masterplan issued by the Italian Government for promoting the use of natural gas as fuel, thus reducing the environmental impact of transport by sea and road. 
The adoption of a system for supplying electrical power to ships moored in port, which allows to switch off the diesel-generators, could be an effective solution to comply with the above-cited maritime rules. On the other hand, the infrastructure and upgrade technologies for supplying modern and sustainable energy services will affect the technical requirements of the ships and the related port activities. Specifically for the port of Genoa, ships' electrical load feeding by the existing grid appears to date an unfeasible solution, due to the high power demand and the actual rating of the electrical distribution infrastructure in the interested area. For this reason, suitable solutions to satisfy ships energy demand in port could be the ones proposed by the authors in this work, and characterized by the adoption of power supply floating units equipped with LNG-fueled generators.

\section{LNG Storage for the Case Study}

The LNG supply infrastructure in the Italian ports is under discussion due to the EU Directives cited above. LNG refueling will be available only in few ports that have to be identified by the authorities. For the present study the authors considered two reasonable alternatives for the port of Genoa:

- a tank directly installed in the port of Genoa;

- a tank located in the port of La Spezia (50 nautical miles from Genoa) where a regasification plant is in service since a long time (Figure 1), using a shuttle tanker to carry the LNG from La Spezia to Genoa.



Fig. 1 Regasification plant in Panigaglia - La Spezia 


\section{Electric Energy Demand in the Old Port of Genoa}

A cleaner source of electric energy to feed ships in port should be designed analyzing the energy demand in the considered area. The first step of this study dealt with the assessment of the electric energy demand of the ships at berth. Starting from collected data regarding the time spent at berth by each ship, an analysis of the calls in the port of Genoa referred to the year 2012 has been carried out.

Ships energy demand at berth has been estimated considering different algorithms according to the several vessel typologies, namely ferries, cruise ships and containerships. For the ferries, a relationship between energy demand and gross tonnage has been considered, while for the cruise ships, the relationship has been based on the onboard maximum installed power. In the case of containerships, the energy demand has been evaluated taking into account the number of TEUs carried onboard. The total amount of electric energy required per year by all the ships considered has been estimated equal to about $54 \mathrm{GWh}$, while it turns out equal to about $48 \mathrm{GWh}$ if the energy required during the time for connection and disconnection operations (Tetra Tech, Inc., 2007 ) is deducted. As it can be noticed in Figure 2, the electric energy demand from ferries is the most significant, being $68 \%$ of the total amount.

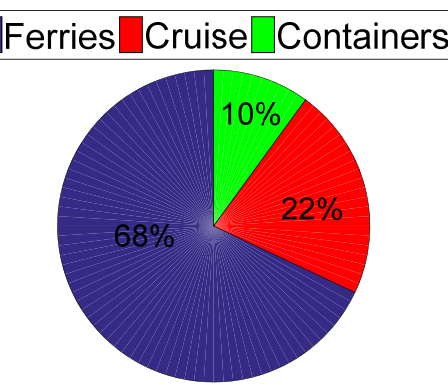

Fig. 2 Electric energy demand in port for several ship typologies - comparison

Figure 3 depicts the energy demand for the three ship typologies during the year 2012, subdivided by calendar months, while in Figure 4 the average daily energy required by ships is presented. 


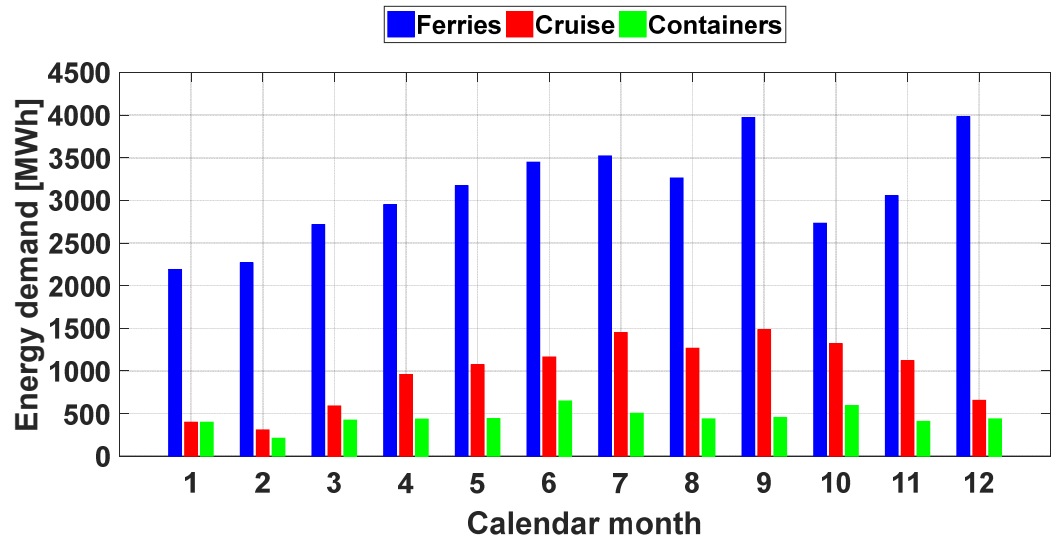

Fig. 3 Monthly electrical energy demand

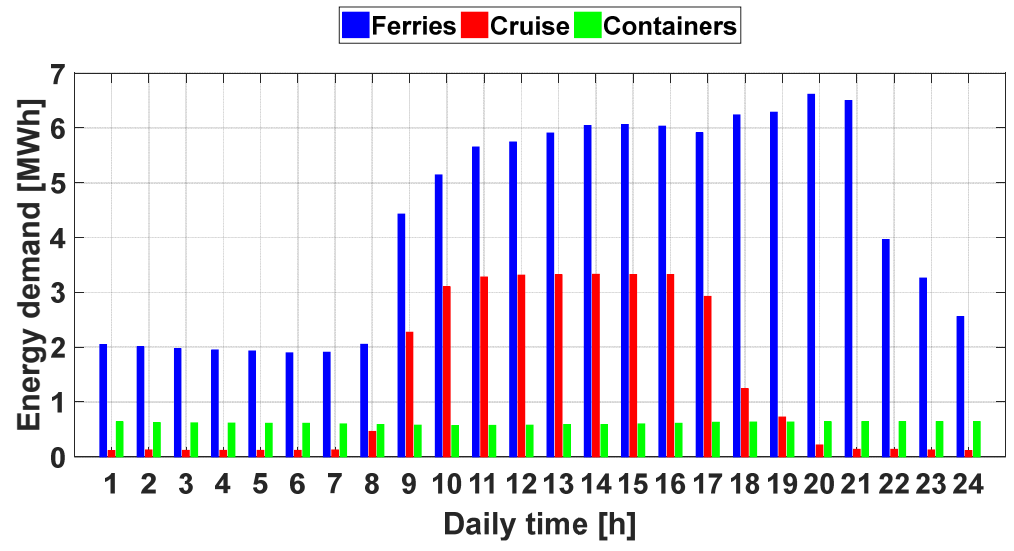

Fig. 4 Average hourly electrical energy demand

Figure 5 shows the distribution of time at berth versus the electric active power demand. As it can be noticed, most of the energy demand is related to electrical loads with power values below 10-15 MW, and if the histogram is analyzed numerically, it turns out that around $85 \%$ of the total energy required by the ships deals with power request equal or below $10 \mathrm{MW}$, being the average about $6 \mathrm{MW}$. 


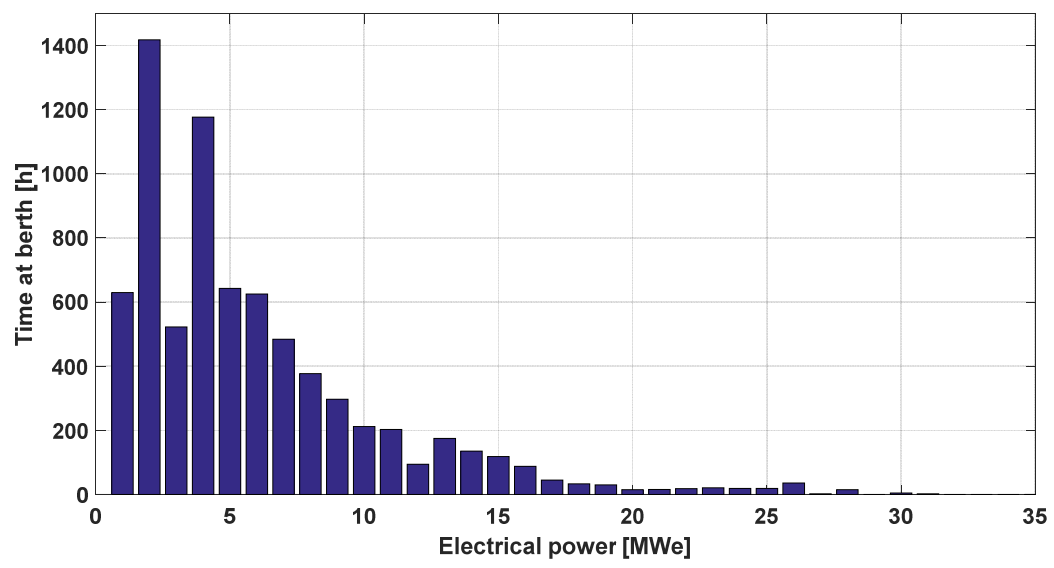

Fig. 5 Distribution of time at berth vs electric power demand

\section{Power Supply Technical Solutions}

If the goal is to satisfy the energy demand of all the ships calling the old port of Genoa, the first option identified by the authors is represented by a fixed power supply barge moored in port, connected to a dedicated network for energy distribution at each berth. In such a way, it would be possible to create a shore-to-ship electrical supply system for distributing electric energy from the main energy source (power supply barge) to the final users. Just as an example, a possible layout of the electrical grid is represented in Errore. L'origine riferimento non è stata trovata., where the location of the power supply barge (PSB) is marked with a white rectangle. Electrical power produced by the barge is convoyed to four main substations (green labels in Figure 6) and then distributed to fourteen terminals (red labels in Figure 6).

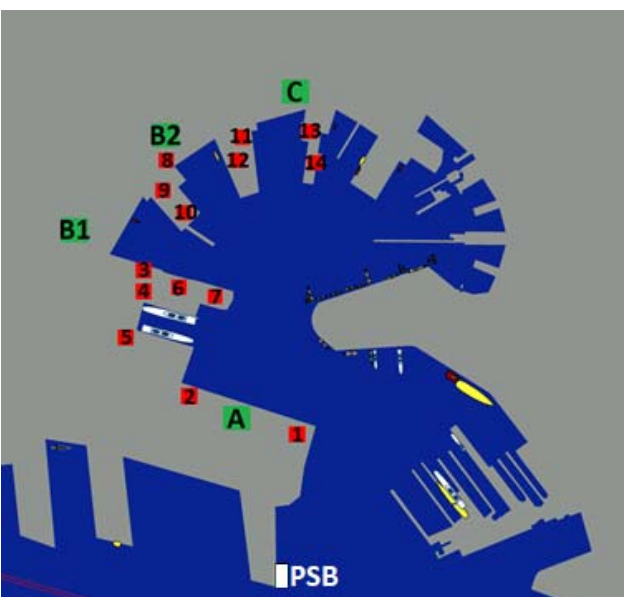

Fig. 6 Port electrical infrastructure. Proposed layout for the old Port of Genoa 
If the goal is to satisfy the energy demand for only a limited number of ships calling the old port of Genoa, the authors identified two technical solutions:

- a towed power supply barge;

- a self-propelled power supply vessel.

In particular, the self-propelled vessel could be a valid solution in case the LNG storage tank is located in the port of La Spezia.

Obviously, these two solutions allow avoiding the installation of the electrical grid ashore because the electric energy produced on-board the power supply barge/vessel can directly supply one or two berthed ships.

Starting from the input data and the considerations previously described and taking into account the three options described in this chapter, a design procedure aimed at exploring feasible solutions has been carried out by the authors. The procedure and the results are detailed in the following chapter.

\section{Power Plant Layout Identification}

In order to carry out the study, a dedicated MATLAB ${ }^{\circledR}$ code has been developed inhouse by the authors. As far as LNG fueled generators are concerned (Altosole, 2017), a database has been implemented and populated with the main features of the generation units produced to date by three different manufacturers (named C,R,W) in the considered power range. Figure 7 shows a simplified scheme of input data and output results of the code. For each of the three options considered (fixed barge, towed barge and selfpropelled vessel), given a configuration in terms of number and power rating of the generation units, the code provides the main characteristics of the power plant, in terms of dimensions and weight, fuel consumption and average load factor, providing also information about generators contemporaneity management to satisfy ships demand and to lower fuel consumption. Moreover, a preliminary and simplified cost estimation is computed as well.

As far as towed barge and self-propelled vessel are concerned, the code automatically selects which ship to feed in case of simultaneous demands. To this aim, the best candidate is the ship characterized by:

- high power demand;

- long layover time in port;

- frequent port calls.

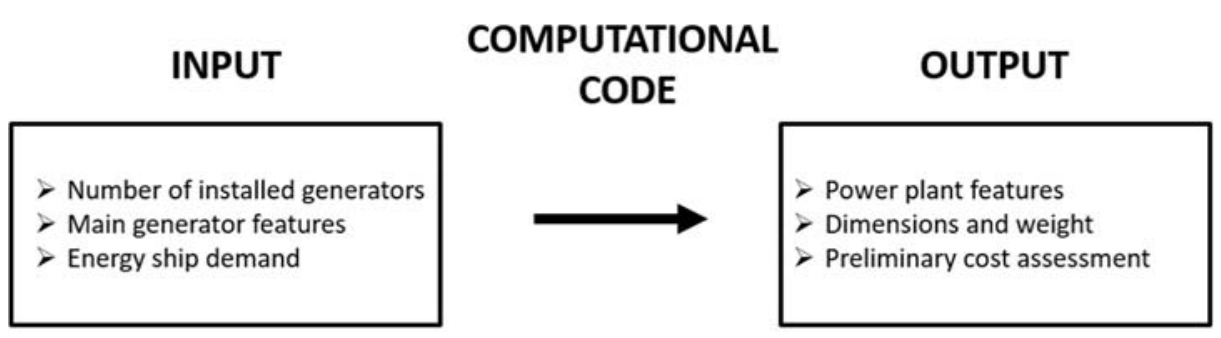

Fig. 7 Code Input data / Output results 
Table 1 provides the results of the analysis for the case study of the old port of Genoa. In particular, the main characteristics of the optimal solution for each floating unit are reported. It is worth mentioning that the layout definition for towed barge and selfpropelled vessel has been identified, introducing a constraint (12 MW) on the maximum electric power generation. The fixed barge, instead, has the capacity to supply all the possible users contemporary, according to the results previously reported in Figure 5.

Table 1. Main characteristics of the possible solutions

\begin{tabular}{|l|r|c|c|c|}
\hline \multicolumn{2}{|c|}{} & $\begin{array}{c}\text { Towed } \\
\text { barge }\end{array}$ & $\begin{array}{c}\text { Self-propelled } \\
\text { vessel }\end{array}$ & $\begin{array}{c}\text { Fixed } \\
\text { barge }\end{array}$ \\
\hline Generators \# and power & {$[\mathbf{M W}]$} & $6 \times 2.1$ & $6 \times 2.1$ & $9 \times 4.2$ \\
\hline Energy & {$[\mathbf{G W h} /$ year] } & 9.3 & 9.3 & 47.9 \\
\hline Efficiency & {$[\%]$} & 46.6 & 46.6 & 45.9 \\
\hline Load factor & {$[-]$} & 0.80 & 0.80 & 0.66 \\
\hline LNG Capacity & {$\left[\mathbf{m}^{3}\right]$} & 200 & 200 & 500 \\
\hline LNG Consumption & {$[$ tons/year] } & 1528 & 1616 & 8307 \\
\hline Displacement & {$[\mathbf{t}]$} & 2435 & 2477 & 5000 \\
\hline Length & {$[\mathbf{m}]$} & 48 & 58 & 64 \\
\hline Beam & {$[\mathbf{m}]$} & 12.5 & 12.5 & 18.2 \\
\hline Draught & {$[\mathbf{m}]$} & 4.3 & 4.3 & 4.4 \\
\hline
\end{tabular}

In the following, a deeper analysis of the detailed results is presented just for the fixed barge option, being the technical solution that can satisfy the energy demand of all the ships calling the considered port area. Figure 8 shows the achievable percent energy coverage as a function of the rated electrical power available for the different layouts investigated. Each dot represents one of the generation configurations, which range from 6 to 10 units of different manufacturers and different rated powers. Considering a maximum power request of about 31.5 MW (as reported in Figure 5), all the configurations (dots) at the right of the vertical red line in the current figure allow to cover $100 \%$ energy demand at port.

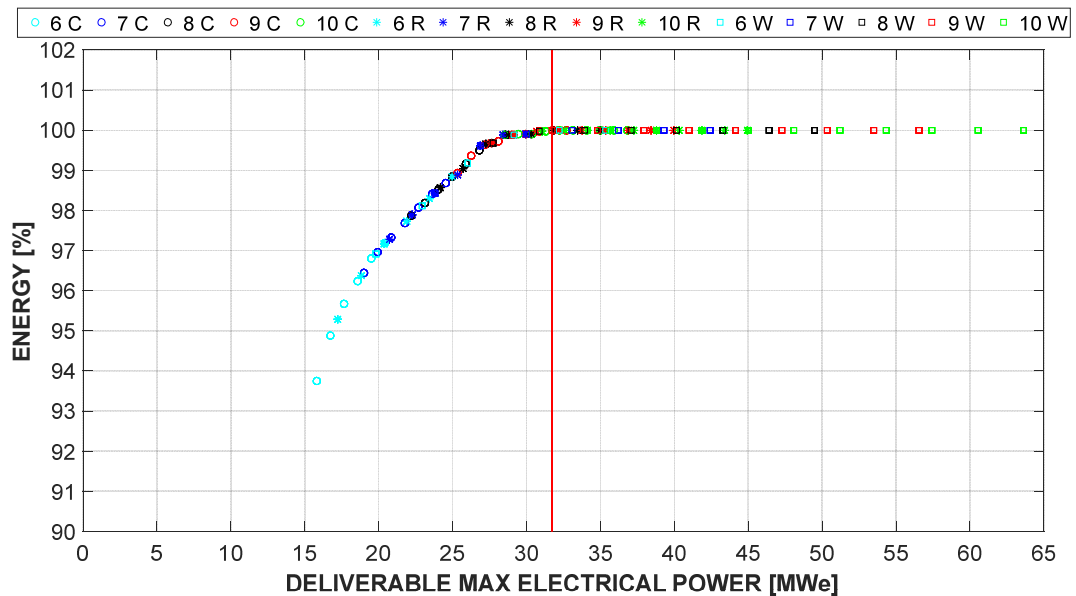

Fig.8 Percent energy coverage vs installed electrical power - fixed barge 
Regarding the barge size and weight, as it can be noticed from Figure 9 and Figure 10 respectively, taking into account a power request of $31.5 \mathrm{MW}$, the length ranges from about 50 to $80 \mathrm{~m}$, while the displacement ranges from 4000 to about 7000 tons, depending on the layout selection.

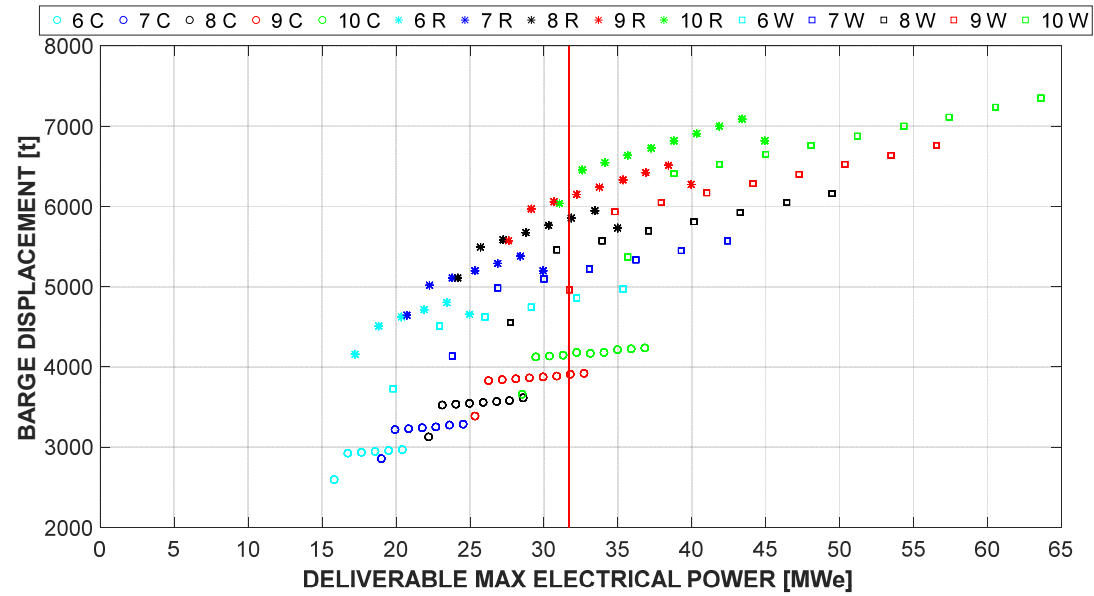

Fig. 9 Length of barge vs installed electrical power - fixed barge

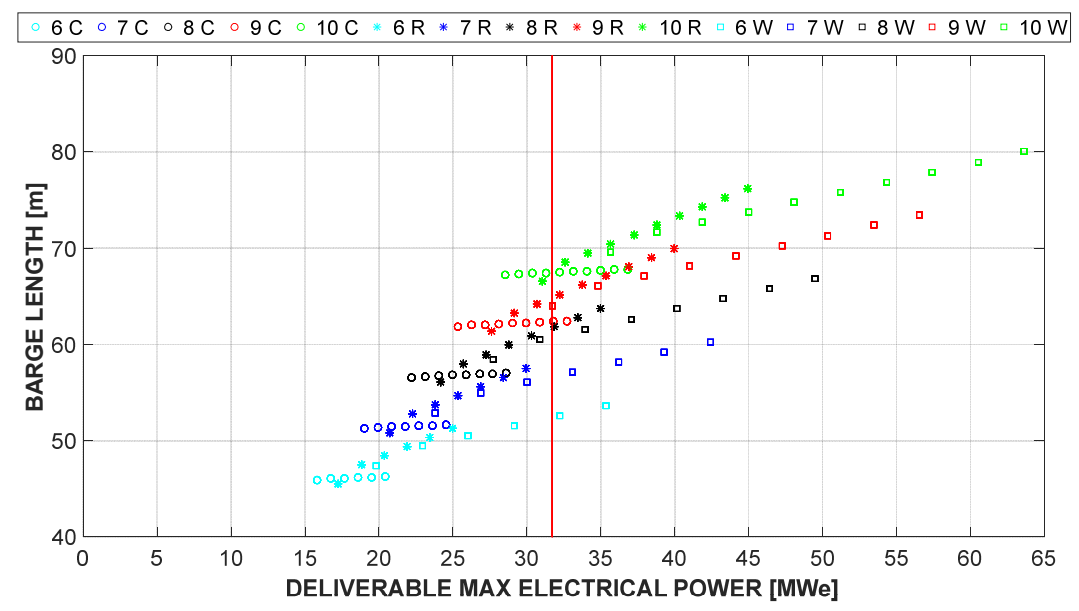

Fig. 10 Deadweight of barge vs installed electrical power - fixed barge

The estimation of the barge displacement $W$ has been carried out considering the sum of four items, as follows:

$$
W=W_{H}+W_{O}+W_{G G}+W_{T} .
$$

where: 
- the weight of hull $W_{H}$ and the weight of outfitting $W_{O}$ has been derived from available data of similar units;

- the weight of gas-fueled generators $W_{G G}$ and LNG on-board tank $W_{T}$ has been derived from the product catalogue.

The evaluation of the main dimensions of the barge has been carried out considering the footprint of the generators and an additional clearance as found in (Potapov V., 2012).

As far as the preliminary cost assessment is concerned, a first estimation of the investment cost has been performed, neglecting cost figure due to the current discount rate. In particular, the investment cost has been computed considering the sum of four items, as reported in relationship (2):

$$
\operatorname{CapEx}=C_{H}+C_{O}+C_{G G}+C_{T \& E} .
$$

where:

- $\quad C_{H}$ is the cost of hull, estimated through the correlation found in (G. Vernengo, E. Rizzuto, 2014);

- $C_{O}$ is the cost of the outfitting, estimated through the technical information collected in (Jack Peckham, 2013);

- $C_{G G}$ is the cost of the gas-fueled electric generator, estimated using the information found in (Masaki A, 2014);

- $\quad C_{T \& E}$ is the cost of LNG tank and gas processing equipment, estimated consulting technical information in (HEC \& CCDTT, 2013).

The specific cost of energy $E C$ has been estimated through equation (3):

$$
E C=\frac{\frac{C a p E x}{L T}+O p E x}{E} .
$$

where:

- $\quad L T$ represents the lifetime of the power barge considered for economic investigations: 30 years is an appropriate value (Kenneth Engblom, 2014);

- $E$ is the energy consumed per year by ships in port;

- $O p E x$ represents the yearly operational costs, estimated by relationship (4):

$$
O p E x=O_{\text {fuel }}+O_{\text {maint }}+O_{\text {lo }}+O_{\text {crew }} .
$$

The cost of fuel $\left(O_{\text {fuel }}\right)$ has been obtained considering a unit value of $307 € /$ ton, while the cost related to the maintenance of generators $\left(O_{\text {maint }}\right)$, lubricating oil $\left(O_{l o}\right)$ and crew $\left(O_{\text {crew }}\right)$ have been found in (V.T.P. Engineering).

The specific cost of energy is reported in Figure 11; taking into account a power demand of $31.5 \mathrm{MW}$ and continuous operations, it shows that a cost of about $0.11 €$ per $\mathrm{kWh}$ could be achieved selecting a fixed barge equipped with 9 generators from manufacturer $\mathrm{W}$ and a rated power of the single unit of 4.2 MW. 


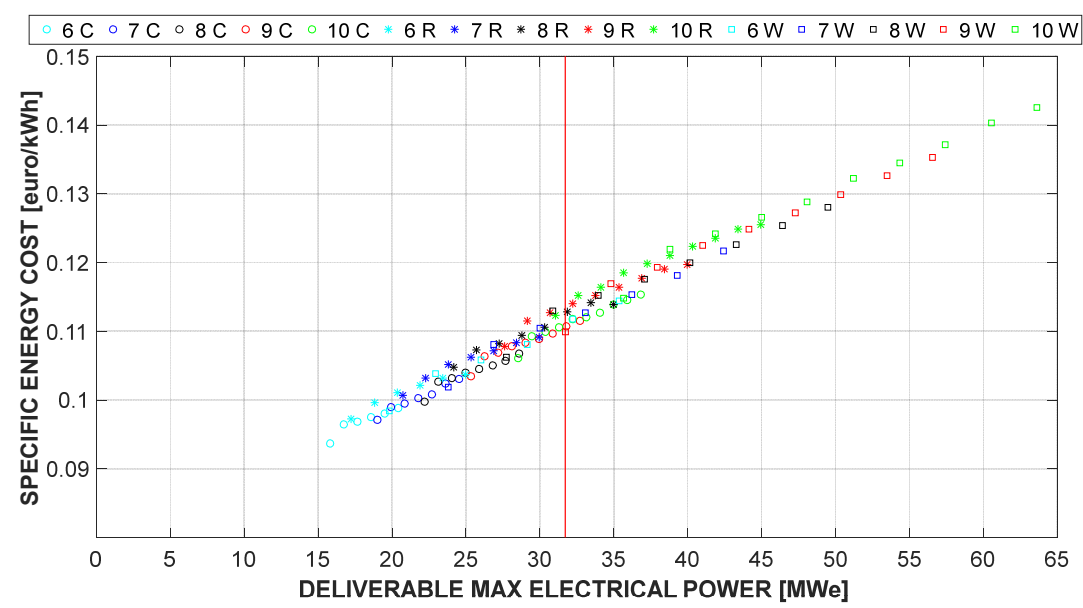

Fig. 11 Specific energy cost vs installed electrical power - fixed barge

It is not easy to predict how many ships could be equipped with an on-board system able to receive energy from the shore connection, so the variation of the specific cost of energy provided by the fixed barge, as a function of the electric energy demand from ships, has been analyzed, and the results are shown in Figure 12. It testifies that if 50\% (or more) of the total energy required by the ships is received from the barge, the proposed solution could be an effective option. An average specific cost of $0.15 € / \mathrm{kWh}$ has been considered for electric energy produced on-board by ships (Levander, O. \& Sipilä, T., 2008).

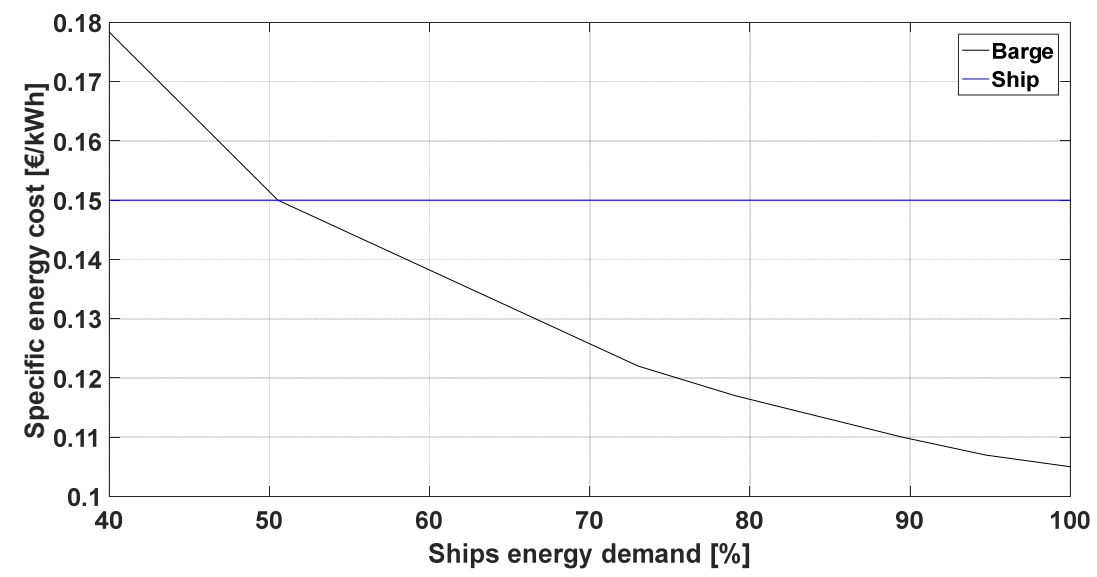

Fig. 12 Fixed barge specific energy cost vs percent ships energy demand

To further cut the specific cost of energy produced by the barge it would be necessary to increase the amount of energy delivered by such a system. Table 2 reports the specific cost of energy produced by the identified configuration of the fixed barge to 
satisfy different requests from both the ships and other ashore industrial activities in port. To this aim the land factor $\alpha_{\mathrm{LF}}$ of Table 2 allows to identify the latter amount of energy delivered by the barge generators $\left(\alpha_{\mathrm{LF}}\right.$ times the amount of energy still remaining, once the ships demand has been satisfied, taking into account the available gross total based on the installed electrical power). In such a context, the table also reports, for the different scenarios, the value of the energy yearly delivered to the ashore industrial activities [GWh] within brackets.

The results of the analyzed case studies show that, if full power is continuously delivered all the year, the minimum cost is achieved, until a value of about $0.07 €$ per $\mathrm{kWh}$. It is fundamental to note that this value cost of energy is very near to the cost of energy provided by the electrical grid in Italy.

Table 2. Specific cost of energy $[€ / \mathrm{kWh}]$ vs ships and ashore activities energy request

\begin{tabular}{|c|c|c|c|c|c|c|c|}
\hline \multirow{2}{*}{$\alpha_{\mathbf{L F}}$} & \multicolumn{7}{|c|}{ Energy yearly delivered to ships [GWh] } \\
& $\mathbf{1 7 . 1}$ & $\mathbf{2 4 . 2}$ & $\mathbf{3 5 . 0}$ & $\mathbf{3 7 . 9}$ & $\mathbf{4 2 . 9}$ & $\mathbf{4 5 . 4}$ & $\mathbf{4 7 . 9}$ \\
\hline \multirow{2}{*}{$\mathbf{0}$} & 0.190 & 0.150 & 0.122 & 0.117 & 0.110 & 0.107 & 0.105 \\
\cline { 2 - 8 } & $(0)$ & $(0)$ & $(0)$ & $(0)$ & $(0)$ & $(0)$ & $(0)$ \\
\hline \multirow{2}{*}{$\mathbf{0 . 2}$} & 0.100 & 0.096 & 0.091 & 0.090 & 0.089 & 0.088 & 0.087 \\
\cline { 2 - 8 } & $(35.5)$ & $(34.1)$ & $(31.9)$ & $(31.3)$ & $(30.4)$ & $(29.9)$ & $(29.4)$ \\
\hline \multirow{2}{*}{$\mathbf{0 . 4}$} & 0.084 & 0.083 & 0.081 & 0.081 & 0.080 & 0.080 & 0.080 \\
\cline { 2 - 8 } & $(71)$ & $(68.1)$ & $(63.8)$ & $(62.7)$ & $(60.7)$ & $(59.7)$ & $(58.8)$ \\
\hline \multirow{2}{*}{$\mathbf{0 . 6}$} & 0.077 & 0.077 & 0.076 & 0.076 & 0.076 & 0.076 & 0.076 \\
\cline { 2 - 8 } & $(106.5)$ & $(102.2)$ & $(95.7)$ & $(94)$ & $(91.1)$ & $(89.7)$ & $(88.2)$ \\
\hline \multirow{2}{*}{$\mathbf{0 . 8}$} & 0.0739 & 0.0737 & 0.0735 & 0.0734 & 0.0733 & 0.0733 & 0.0732 \\
\cline { 2 - 8 } & $(142)$ & $(136.2)$ & $(127.7)$ & $(125.3)$ & $(121.4)$ & $(119.5)$ & $(117.6)$ \\
\hline \multirow{2}{*}{$\mathbf{1}$} & 0.0713 & 0.0713 & 0.0713 & 0.0713 & 0.0713 & 0.0713 & 0.0713 \\
\cline { 2 - 8 } & $(177.4)$ & $(170.3)$ & $(159.6)$ & $(156.6)$ & $(151.8)$ & $(149.4)$ & $(146.9)$ \\
\hline
\end{tabular}

\section{Reduction of Air Pollutant Emission}

The calculation of air pollutant emission by ships at berth in the old port of Genoa has been performed through the emission factor as reported in the literature (Yorke engineering, 2007). Table 3 reports the amount of the main pollutants for the different scenarios investigated in this study (all the ship supplied by the fixed barge, or the maximum ships that can be supplied by the towed/self propelled barges), as well as for the actual situation where berthed ships use MGO as fuel for diesel generators.

Table 3. Air pollutant emission for different scenarios [tons/year]

\begin{tabular}{|c|c|c|c|}
\hline & Using MGO as fuel & $\begin{array}{c}\text { Cold ironing } \\
\text { (Fixed barge) }\end{array}$ & $\begin{array}{c}\text { Cold ironing } \\
\text { (Barge towed or self-propelled } \\
\text { vessel) }\end{array}$ \\
\hline NOx & 829 & 257 & 718 \\
\hline PM 10 & 25 & 3.0 & 21 \\
\hline PM 2.5 & 13.7 & 1.6 & 11.4 \\
\hline SOx & 122 & 15 & 101 \\
\hline
\end{tabular}


It is to be noticed that a lower reduction is achieved by means of the towed barge and self-propelled vessels because of the lower electrical energy supplied by gas-fueled 262 generators.

\section{Conclusions}

264 The paper presents technical solutions to feed ships' electric systems in port by means of LNG supplied power generation systems. Three different solutions have been identified and analyzed for a case study related to the old port of Genoa. From the study, it turns out that a generation plant installed on a fixed barge could be a valid option for supplying energy to all the ships at berth. Taking into account that in the considered port some issues do not allow to directly feed ships electrical equipment by the national grid, the fixed barge option could be a good solution to satisfy the overall ships energy request, lowering the pollutants emission in port. An alternative could be represented by the adoption of the towed barge and/or self-propelled vessel, which need a lower capital investment and are characterized by smaller dimensions and weight. On one hand, due to their size, such latter solutions can offer flexibility of movement in port and allow to feed ships by approaching each of them. On the other hand, they can supply energy just to a reduced number of ships and do not allow to achieve the same performances of the fixed barge solution, in terms of air pollutant reduction in port. In any case, whatever is the adopted solution, ashore connection of ships for energy purposes through solutions fueled by LNG seems an effective alternative to make the port and the surrounding environment more ecofriendly. The introduction of this fuel in the maritime sector could also represent a pull factor for all the ship-owners interested to switch on a greener energy for moving cargo and passenger in a new era. 


\section{References}

Altosole, M., Benvenuto, G., Campora, U., Laviola, M., Zaccone, R. (2017) Simulation and performance comparison between diesel and natural gas engines for marine applications (2017) Proceedings of the Institution of Mechanical Engineers Part M: Journal of Engineering for the Maritime Environment, 231 (2), pp. 690-704.

Coraddu, A., Figari, M., Savio, S. (2014) Numerical investigation on ship energy efficiency by Monte Carlo simulation, (2014) Proceedings of the Institution of Mechanical Engineers Part M: Journal of Engineering for the Maritime Environment, 228 (3), pp. $220-234$.

G. Vernengo, E. Rizzuto. (2014) Ship synthesis model for the preliminary design of a fleet of compressed natural gas carriers. Ocean Engineering 89 (2014) 189-199

HEC, CCDTT. (2013) LNG as Ship Fuel, Effects on ship design, operations and supporting infrastructure.

Jack Peckham (2013) Becker Touts 'World's First Hybrid LNG Barge' for Cold-Ironing Cruise Ships. Diesel fuel News

Kenneth Engblom (2014) Feautures and paramenters of various power plant technologies. Wärtsilä Technical Journal.

Levander, O., Sipilä, T. (2008) LNG auxiliary power in port for container vessels, Wärtsilä Technical Journal, February 2008, pp. 42-47.

Masaki A., Hiroyuki K., Tetsugo F., Shota O., Kazuyoshi H., (2014) Economic analysis of trans-ocean LNG fueled. J Mar Sci Technol 19:470-478. doi:10.1007/s00773-014$0262-5$

Potapov V. (2012) DF Integrated propulsion system and LNG pack - Technical developments, benefits and operational experience. Wartsila http://www.korabel.ru/filemanager/OTHER/0/0/7.pdf

V.T.P. Engineering COLD IRONING, Una nuova soluzione eco-compatibile per l'alimentazione delle navi in porto.

Yorke engineering, 2007. Port of San Diego: Cold ironing study. 